\title{
A new compilation of stomach content data for commercially important pelagic fish species in the northeast Atlantic
}

\author{
J. K. Pinnegar ${ }^{1}$, N. Goñi ${ }^{2}$, V. M. Trenkel ${ }^{3}$, H. Arrizabalaga ${ }^{2}$, W. Melle ${ }^{4}$, J. Keating ${ }^{5}$, and G. Óskarsson ${ }^{6}$ \\ ${ }^{1}$ Centre for Environment, Fisheries \& Aquaculture Science (Cefas), Pakefield Road, Lowestoft, Suffolk, \\ NR33 OHT, UK \\ ${ }^{2}$ AZTI Fundazioa, Herrera kaia Portualdea z/g, 20110 Pasaia, Gipuzkoa, Spain \\ ${ }^{3}$ Institut français de recherche pour l'exploitation de la mer (IFREMER), BP 21105, 44311 Nantes, France \\ ${ }^{4}$ Institute of Marine Research (IMR), P.O. Box 1870 Nordnes, 5817 Bergen, Norway \\ ${ }^{5}$ Marine and Freshwater Research Centre, Galway-Mayo Institute of Technology (GMIT), Galway, Ireland \\ ${ }^{6}$ Marine Research Institute (MRI), Skulagata 4, 121 Reykjavik, Iceland
}

Correspondence to: J. K. Pinnegar (john.pinnegar@cefas.co.uk)

Received: 9 January 2014 - Published in Earth Syst. Sci. Data Discuss.: 14 April 2014

Revised: 19 December 2014 - Accepted: 12 January 2015 - Published: 13 February 2015

\begin{abstract}
There is increasing demand for information on predator-prey interactions in the ocean as a result of legislative commitments aimed at achieving sustainable exploitation. However, comprehensive data sets are lacking for many fish species and this has hampered development of multispecies fisheries models and the formulation of effective food-web indicators. This work describes a new compilation of stomach content data for five pelagic fish species (herring, blue whiting, mackerel, albacore and bluefin tuna) sampled across the northeast Atlantic and submitted to the PANGAEA open-access data portal (www.pangaea.de). We provide detailed descriptions of sample origin and of the corresponding database structures. We describe the main results in terms of diet composition and predator-prey relationships. The feeding preferences of small pelagic fish (herring, blue whiting, mackerel) were sampled over a very broad geographic area within the North Atlantic basin, from Greenland in the west, to the Lofoten Islands in the east and from the Bay of Biscay northwards to the Arctic. This analysis revealed significant differences in the prey items selected in different parts of the region at different times of year. Tunas (albacore and bluefin) were sampled in the Bay of Biscay and Celtic Sea. Dominant prey items for these species varied by location, year and season. This data compilation exercise represents one of the largest and most wide-ranging ever attempted for pelagic fish in the North Atlantic. The earliest data included in the database were collected in 1864, whereas the most recent were collected in 2012. Data sets are available at doi:10.1594/PANGAEA.820041 and doi:10.1594/PANGAEA.826992.
\end{abstract}

1

Food webs have become a major focus for EU research and maritime policy. The 2008 European Union Marine Strategy Framework Directive (2008/56/EC) includes a commitment that member states should work to achieve "Good Environmental Status" (GES) by 2015. This is defined by 11 qualitative descriptors, one of which (descriptor 4) explicitly focuses on "Food Webs". In addition, documents concern- ing reform of the EU "Common Fisheries Policy" (e.g. EC, 2011) have acknowledged that "Fisheries management must ... follow the ecosystem and precautionary approach" and this has been interpreted as requiring information on interactions between species (ICES, 2013). Multispecies food-web models are seen as crucial for addressing this new agenda, yet there are surprisingly few long-term data sets available for parameterizing models of predator-prey interactions in the ocean. There is growing demand for data on "who eats 
whom" in marine systems, in order to deduce how changes in one part of the ecosystem might have consequences elsewhere.

EU member states made a commitment as part of the Johannesburg Declaration on Sustainable Development to work towards maximum sustainable yield (MSY) for all fish stocks by 2015 . However, modelling studies have demonstrated that it is highly unlikely that all stocks can be maintained at precautionary MSY reference points simultaneously because individual species eat each other (Mackinson et al., 2009), and thus the very high yields predicted at low fishing pressure by single-species models would be eroded by predation pressure. Consequently, ICES have stated that "Stomach data are of vital importance" and that it intends to gradually transition to providing multispecies advice on fisheries for some European ecosystems in the near future (ICES, 2013). A number of coordinated fish stomach databases do exist to help facilitate this task, but these typically encompass only a limited selection of species or cover a very discrete period of time. One of the more extensive data sets is the ICES "Year of the Stomach" database for the North Sea, which provides information on 35 species, although detailed data are only available for nine, primarily based on stomachs collected during sampling campaigns in 1981 and 1991. A similar coordinated ICES data set exists for cod in the Baltic Sea and has been documented in ICES (1997). In the Barents Sea, a combined database exists for Norway and Russia (Dolgov et al., 2007), but in all cases these sources offer limited information on pelagic fishes (i.e. those living at or near the surface of the ocean) and especially those with a wide geographic distribution.

The EU EURO-BASIN project aims to understand and predict the dynamics of plankton-feeding and pelagic fish species in the North Atlantic, and to assess the impacts of climate variability. This project has a particular focus on herring (Clupea harengus), mackerel (Scomber scombrus) and blue whiting (Micromesistius poutassou), which are the most abundant and widespread planktivorous fish species in the region, as well as bluefin tuna (Thunnus thynnus) and albacore (Thunnus alalunga), top predator species that inhabit the whole North Atlantic basin and carry out trans-oceanic migrations.

In the present paper we provide details of newly digitized information on the diet of these five species, firstly from the UK DAPSTOM database (mackerel, herring and blue whiting), that incorporates information from recent research cruises by the Institute of Marine Research (IMR, Norway), Marine Research Institute (MRI-HAFRO, Iceland), Institut français de recherche pour l'exploitation de la mer (IFREMER, France), Marine Institute (Ireland), as well as historic data from the Centre for Environment, Fisheries and Aquaculture Science (Cefas) in the UK. We also examine data from AZTI-Tecnalia (Spain) on bluefin tuna and albacore stomach contents. Data sets derived under the EURO-BASIN project have been submitted to, and are available via, the
PANGAEA open-access data portal (www.pangaea.de, Pinnegar et al., 2013; Goñi, 2014).

\section{Data and methods}

The two data sets described here provide information on feeding preferences of 27746 individual herring, 7423 mackerel, 1126 blue whiting, 1526 albacore and 689 bluefin tuna. Samples have been obtained from scientific research surveys using a variety of different fishing gears, from commercial fishery catches, and from individual fish voluntarily sampled by recreational fishermen. In the following two sections we describe the origins of the data and database structures as well as the geographical and temporal coverage.

\subsection{The DAPSTOM database}

The DAPSTOM database has been in existence for 8 years, having been created in response to a "data-rescue" call from the EU "Network of Excellence" project EUROCEANS. The most recent version of the DAPSTOM data set (Version 4.7, collated in January 2014) includes 226407 records derived from 449 distinct research cruises, spanning the period 18372012. The database contains information from 254202 individual predator stomachs and 188 species. As such, this represents one of the largest and most diverse compilations of food-web information anywhere in the world. A key component of the DAPSTOM programme has been an online data portal (www.cefas.defra.gov.uk/fisheries-information/ fish-stomach-records.aspx) through which outputs are made freely available to the wider scientific community. In addition, a subset of the pelagic fish information contained in the full DAPSTOM database has now been made available via PANGAEA (doi:10.1594/PANGAEA.820041; Pinnegar et al., 2013).

As the DAPSTOM initiative has progressed, a relationaldatabase structure has evolved (in Microsoft Access) that can accommodate all formats of stomach content information (see Hyslop, 1980), including data collected at the level of individual fish, pooled samples of multiple fish stomachs, frequency of occurrence data as well as fully gravimetric information (prey weights or volumes). As a minimum, in Version 4.7 of the DAPSTOM database, information on the predator species, geographic area and the number of stomachs examined was required for a data set to be included. Information on predator length (or size range) was also widely available.

Central to the relational-database structure is the "DAPSTOM" data table (Fig. 1). This includes much of the "raw" information about both the predator and prey. The "DAPSTOM" data table includes 23 information fields (Fig. 1), and a full definition of each field is provided by Pinnegar (2014). The "HAULS" table contains all information about the geographic location from which the sample was derived. In most cases this includes ship name, dates and 


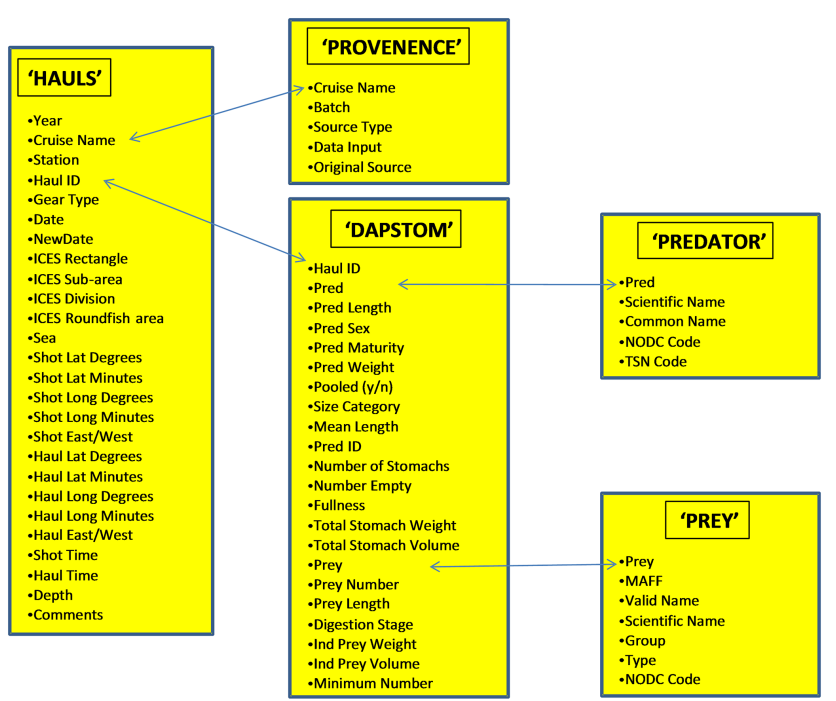

Figure 1. Structure of the DAPSTOM 4.7 relational database, including a list of the fields contained within each table. For a full description of the field formats and nomenclature see Pinnegar (2014).

times, latitudes, longitudes, depth, gear type, ICES area and any additional information. Each "haul" has been assigned to a predefined "Sea" (e.g. North Sea, Irish Sea, W Ireland, Celtic Sea, Channel, Biscay etc.) and ICES "Division" - a spatial sub-unit used by the International Council for the Exploration of the Sea. Note that Tables 1 and 2 do not provide detailed information about sampling time and date, but that this information is available in the underlying PANGAEA and DAPSTOM data sets that are freely available online. In Figs. 3-5 we have not controlled for time of day or season, but this would be possible if desired.

A new innovation within version 4.7 of the DAPSTOM database is the inclusion of a "PROVENANCE" look-up table (Fig. 1). The purpose of this is to record the origin of the data, for example whether or not the data were derived from published sources or based upon "raw" data files from collaborating scientists. Two additional look-up tables have been created to help standardize the taxonomic information that is available to users. The "PREDATOR" look-up table expands on the 3-digit predator names in the "DAPSTOM" table and gives the predator's full Latin name, common name (in English), 10-digit NODC code and TSN identifier. The "PREY" look-up table aims to reduce the enormous number of potential prey names and descriptions to a manageable number of standardized names that can be used for analyses and collation. It corrects historic taxonomy to modern counterparts, and allows aggregation by broad prey groups (e.g. euphausids, amphipods, copepods, teleosts etc.).

The DAPSTOM data set has now seen wide usage among ICES Working Groups as well as in a number of theoretical ecology papers (e.g. Rochet et al., 2011; Rossberg et al., 2011; Brose et al., 2006). On the whole, researchers have used the online portal to look at the diet composition of their favoured predator species - however there has also been some interest in making use of historical data sets to determine long-term changes in fish diets at particular localities (Le Quesne and Pinnegar, 2012).

\subsection{The AZTI tuna stomach database}

The feeding ecology of temperate tunas (albacore Thunnus alalunga and bluefin tuna Thunnus thynnus) in the Bay of Biscay has been investigated through several projects in AZTI-Tecnalia since the mid-2000s. Although there has been little continuity between the projects dealing with the feeding ecology of temperate tunas, a total of 1525 stomachs have been sampled from albacore and 686 stomachs from bluefin tuna between 2004 and 2011.

The sample origin and methodologies employed have been diverse. Samples were collected:

1. during albacore acoustic tracking surveys (summer 2005), albacore dummy archival tagging surveys (summers 2005 and 2006), albacore archival tagging survey (June 2010), bluefin tuna tagging surveys $(2009,2011$, 2012). In the case of these samples the location and the hour of each capture was included in the database.

2. through collaborating recreational fishermen in the southeastern Bay of Biscay in 2005, 2006 and 2007.

3. through opportunistic sampling by the canning industry for albacore $(2005,2006,2010,2011)$ and in wholesalers stores for bluefin tuna $(2009,2010,2011,2012)$. In this case, the catch dates and estimated locations of each predator were re-constructed a posteriori using information contained in the logbook of each fishing vessel. No catch hour was recorded in the case of these commercial catches, and the estimated locations correspond to the centres of the ICES statistical rectangles recorded in the logbooks.

The gears used to catch each sampled tuna also differed considerably, and included: (1) rod and reel (RR) primarily used by recreational fishermen; (2) trolling gear (TR) used during albacore tagging surveys; (3) pole and line with live bait (BB), used for most bluefin tuna catches (commercial and surveys) and for part of the commercial albacore catch, (4) pelagic trawl (MWT) used for a further part of the commercial albacore catch.

Due to the lower number of predators sampled in the case of tunas (in comparison with small pelagic fishes such as herring, blue whiting and mackerel), the relatively restrained geographical location of the samples (mostly Bay of Biscay) especially in the case of bluefin tuna, we chose not to include the tuna data in the DAPSTOM data portal but rather to build a simple database in XML format held at AZTI-Tecnalia, but also uploaded to PANGAEA 
Table 1. Number of stomach content records for pelagic fish species submitted to the DAPSTOM database as part of EURO-BASIN. Number of individual stomachs included in parentheses.

\begin{tabular}{llllllll}
\hline Data set & Period & Months & Herring & Blue whiting & Mackerel & Albacore & Bluefin tuna \\
\hline IFREMER (France) & 2011 & Oct & $0(0)$ & $133(117)$ & $0(0)$ & $0(0)$ & $0(0)$ \\
IMR (Norway) & 2004,2006 & Jul, Aug & $1291(538)$ & $354(139)$ & $1772(635)$ & $0(0)$ & $0(0)$ \\
MRI (Iceland) & 2010,2011 & Jul, Aug & $1610(823)$ & $274(158)$ & $3226(1486)$ & $0(0)$ & $0(0)$ \\
GMIT (Ireland) & 2011 & Nov, Dec & $0(0)$ & $139(109)$ & $0(0)$ & $0(0)$ & $0(0)$ \\
Cefas (UK) & 2010,2011 & Feb, Mar & $1101(961)$ & $467(366)$ & $6(3)$ & $0(0)$ & $0(0)$ \\
Cefas - Historical & $1864-2009$ & All months & $4506(25424)$ & $216(237)$ & $5614(5299)$ & $1(1)$ & $10(3)$ \\
\hline Total & & & $8508(27746)$ & $1583(1126)$ & $10618(7423)$ & $1(1)$ & $10(3)$ \\
\hline
\end{tabular}

(doi:10.1594/PANGAEA.826992; see Goñi, 2014). The tuna stomach database is provided as a single table, each row corresponding to a single predator. For each predator, the information provided included the species, the sample origin (survey or opportunistic sampling), the catch date and location (either measured or assigned according to logbook information), the size and weight, and the gear used for the catch.

\section{Results - data submitted to PANGAEA under the EU project EURO-BASIN}

\subsection{DAPSTOM data set}

Throughout 2013, EURO-BASIN partners submitted data sets to the lead author of this paper and these were reformatted into the required DAPSTOM relational tables (Fig. 1). Data sets made available as part of EURO-BASIN can be summarized as follows.

It is clear that the vast majority of the blue whiting data within the DAPSTOM database were collected in recent years, and explicitly for the purposes of EURO-BASIN (1367 records out of 1583), whereas this was not true for herring or mackerel (Table 1). It is also apparent from Tables 1 and 2 that for blue whiting and mackerel the number of database records exceeded the number of stomachs examined, confirming that the data were largely non-pooled records from individual stomachs whereas this was not true for herring where 8508 database records were derived from 27746 stomachs. The primary explanation for this disparity is the digitization of "pooled" herring data sets from a historical report by Hardy (1924), but also "pooled" data from Brook and Calderwood (1886) and Scott (1924).

Table 2 shows the number of records and samples by geographic area (Fig. 2), including all larval and juvenile fish. From this table it is apparent that herring, blue whiting and mackerel have been sampled over a huge geographic area, spanning from the Bay of Biscay $\left(\sim 43^{\circ} \mathrm{N}\right)$, to the high Arctic $\left(\sim 73^{\circ} \mathrm{N}\right)$ and from Greenland in the west $\left(\sim 29^{\circ} \mathrm{W}\right)$ to the Lofoten islands in the east $\left(\sim 9^{\circ} \mathrm{E}\right)$. By contrast, the very limited number of records for albacore and bluefin tuna in the
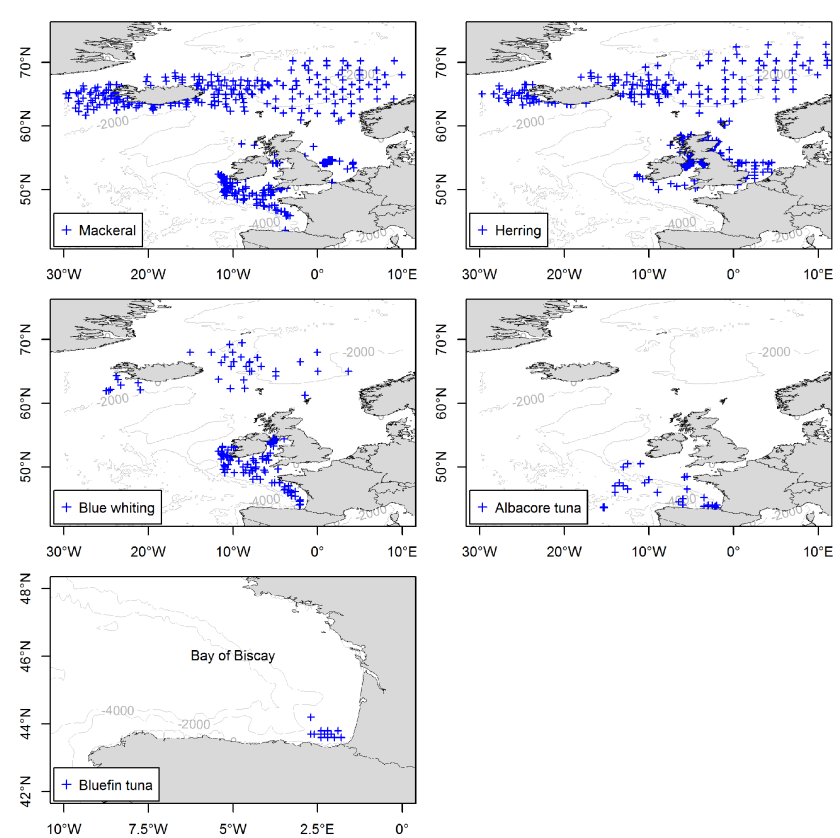

$30^{\circ} \mathrm{W} \quad 20^{\circ} \mathrm{W}$

Figure 2. Location of stomach content samples (circles) for the five pelagic species collected in the northeast Atlantic and submitted to the DAPSTOM and AZTI databases.

DAPSTOM database were derived from opportunistic sampling in the English Channel and North Sea.

The earliest of the data included in the DAPSTOM/EUROBASIN data set is a single record of an albacore tuna stranded on the Channel coast of England in August 1864, whereas the most recent of the data comes from a single bluefin tuna stranded at Ventnor, Isle of Wight in August 2012. The data set includes information on the feeding preferences of fish larvae ( 0.1 to $10 \mathrm{~cm}$ in length), as well as adult fish. Specifically, the feeding habits of larval/juvenile herring and mackerel from Plymouth Sound, the Clyde and the North Sea by Lebour (1921, 1924), Marshall et al. (1937, 1939) and Last (1980) respectively. 
Table 2. Number of records for pelagic fish species submitted to the DAPSTOM stomach content database as part of EURO-BASIN, by geographic region. Number of individual stomachs included in parentheses.

\begin{tabular}{llllll}
\hline ICES Region (Sea) & Herring & Blue whiting & Mackerel & Albacore & Bluefin tuna \\
\hline VIIIa, b, c (Bay of Biscay) & $0(0)$ & $157(139)$ & $896(598)$ & $0(0)$ & $0(0)$ \\
VIIf, g, h, j (Celtic Sea) & $66(59)$ & $506(411)$ & $2804(2416)$ & $0(0)$ & $0(0)$ \\
VIIe, d (Channel) & $577(5077)$ & $35(24)$ & $718(789)$ & $1(1)$ & $1(1)$ \\
XIVa, b (E Greenland/N Iceland) & $605(246)$ & $70(29)$ & $1050(432)$ & $0(0)$ & $0(0)$ \\
Va (Iceland) & $680(405)$ & $105(72)$ & $1356(672)$ & $0(0)$ & $0(0)$ \\
VIIa (Irish Sea) & $1294(1285)$ & $183(166)$ & $29(19)$ & $0(0)$ & $0(0)$ \\
XII (North Atlantic) & $0(0)$ & $18(9)$ & $0(0)$ & $0(0)$ & $0(0)$ \\
IVa, b, c (North Sea) & $2954(16480)$ & $19(49)$ & $1106(1225)$ & $0(0)$ & $9(2)$ \\
IIa (Norwegian Sea) & $1616(710)$ & $435(187)$ & $2447(987)$ & $0(0)$ & $0(0)$ \\
VIIb (western Ireland) & $0(0)$ & $55(40)$ & $129(116)$ & $0(0)$ & $0(0)$ \\
VIa (western Scotland) & $716(3484)$ & $0(0)$ & $83(169)$ & $0(0)$ & $0(0)$ \\
\hline
\end{tabular}

\subsection{AZTI-Tecnalia data set}

The tuna stomach database from AZTI-Tecnalia corresponds to 7 years of sampling from 2004 to 2011. Due to the absence of continuity in the different projects dealing with the feeding ecology of tunas, the sampling could not be performed every year for both species, and no samples were collected in 2008. The lack of temporal continuity is more apparent for bluefin tuna than for albacore. However, a total of 1525 albacore and 686 bluefin tuna stomachs were collected during the study period (Table 3 ).

\section{Discussion}

A major limitation of the DAPSTOM data set is that it includes a mixture of "pooled" information as well as data collected from individual fish. Sometimes only information on the number of stomachs containing a particular prey item was available (i.e. "frequency of occurrence"), rather than the actual number of a particular prey item. Hence in any data extraction, outputs should be viewed as providing information on the "minimum number" of prey items consumed. This would have little impact in predator species that consume large prey items one at a time (e.g. fish feeders), but also with regard to most of the newer data sets assembled under EURO-BASIN. However, it could be that in certain older data sets, the total number of prey items in plankton-eating species such as mackerel, herring and blue whiting would be underestimated. An example would be the historical data set containing mackerel stomachs off the Cornish coast from Bullen (1908) a component of the "Cefas Historical" records cited in Table 1, as well as the herring data sets digitized from Marshall et al. (1937, 1939).

A further limitation of the DAPSTOM database is paucity of information on prey weights. In many of the constituent data sets no gravimetric information was provided. A consequence of this is that it can be difficult to judge the importance of a particular prey item to the overall nourishment of the predator, since a mackerel for example, may draw significantly more nourishment from eating a single fish in comparison with $1000+$ copepods. To remedy this situation, we plan to develop an updated "PREY" table (see Fig. 1) that includes average prey weights, and perhaps energy density for each standardized prey type so that numbers consumed can be converted to total weights. However this feature is not yet available.

Several authors have suggested that the preferred prey of blue whiting are euphausiids and hyperiid amphipods, although the relative importance of each of these varies depending on season and locality (Prokopchuk and Sentyabov, 2006; Langøy et al., 2012). The EURO-BASIN data set (Tables 1 and 2) shows similar variability in diet composition depending on sampling location (Fig. 3), with euphausids dominating in terms of number in Iceland, the Bay of Biscay and the Irish Sea, but hyperiid amphipods dominating in the Norwegian Sea, eastern Greenland/northern Iceland (ICES SubArea XIV) and the Celtic Sea. Copepods (mainly Calanus finmarchicus) were an additional important prey item in the Norwegian Sea and shrimps (in particular Pasiphaea sivado) were commonly observed in stomachs from the Irish Sea. Adult blue whiting from throughout the north Atlantic migrate in the springtime, to the Porcupine and Rockall areas west of Ireland. During this season they feed very infrequently.

Post-larval mackerel feed on a variety of zooplankton and small fish. Published sources suggest that the main zooplankton prey organisms in the North Sea are copepods (mainly Calanus finmarchicus) and euphausiids (mainly Meganyctiphanes norvegica), while fish prey include larval sand eel, herring and sprat (Mehl and Westgård, 1983). In the Norwegian Sea published sources suggest that euphausiids, copepods, pteropod molluscs (Limacina retroversa), amphipods, Appendicularia and capelin are the main dietary items (Langøy et al., 2012; Prokopchuk and Sentyabov, 2006). The EURO-BASIN data set confirms these broad patterns (Fig. 4), and in every geographic region for which data 
Table 3. Number of stomach content records for albacore and bluefin tuna, sampled in the Bay of Biscay and submitted to the AZTI tuna stomach database as part of EURO-BASIN, by year and fishing gear.

\begin{tabular}{clrr}
\hline Year & Sample source (gear) & Albacore & Bluefin tuna \\
\hline 2004 & Commercial fishery (BB) & 0 & 32 \\
2005 & Sonic tracking and archival tagging surveys (TR) & 166 & 12 \\
2005 & Recreational fishermen (RR) & 162 & 24 \\
2005 & Commercial fishery (MWT) & 69 & 0 \\
2006 & Archival tagging survey & 49 & 0 \\
2006 & Recreational fishermen & 68 & 3 \\
2006 & Commercial fishery (MWT) & 79 & 0 \\
2007 & Recreational fishermen (RR) & 37 & 0 \\
2009 & Commercial fishery (albacore MWT, bluefin BB) & 95 & 238 \\
2009 & Archival tagging survey & 0 & 19 \\
2010 & Commercial fishery (TR, BB, MWT) & 532 & 233 \\
2010 & Archival tagging survey & 34 & 0 \\
2011 & Commercial fishery (TR, BB, MWT) & 234 & 68 \\
2011 & Conventional tagging survey (BB) & 0 & 57 \\
\hline & $\quad$ Total & 1525 & 686 \\
\hline
\end{tabular}

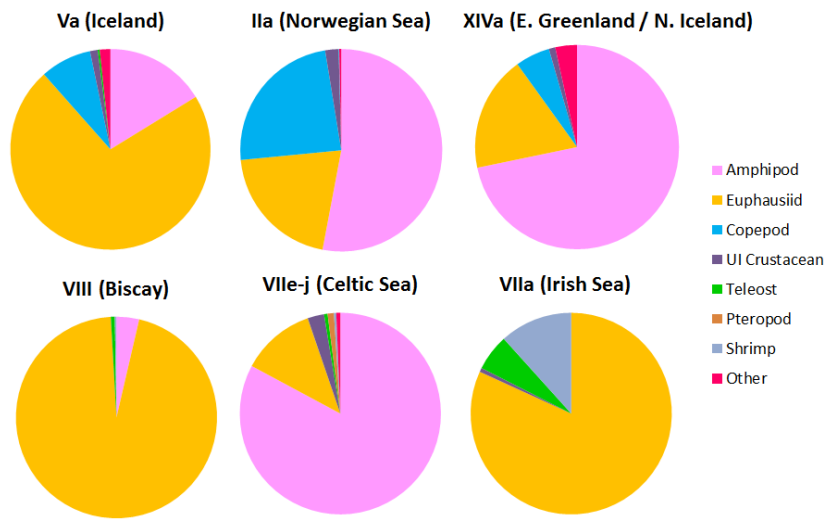

Figure 3. Diet composition of blue whiting Micromesistius poutassou in different parts of the northeast Atlantic (ICES Divisions). Proportions are based on the number of individual prey items.

were available (Table 2), with the exception of the Bay of Biscay, copepods dominated in terms of numerical abundance, especially in Iceland $(91 \%)$. However, mysids and hyperiid amphipods contributed a significant additional proportion to the diet of mackerel in the North Sea $(16 \%)$. Hyperiids and euphausids contributed a significant additional proportion to the diet in East Greenland/North Iceland (ICES Sub-Area XIV, $32 \%$ ) and phytoplankton, teleosts and chaetognaths contributed a significant proportion in the Celtic Sea (27\%). In the Bay of Biscay, $67 \%$ of the diet composition (by number) was suggested to comprise mackerel eggs (denoted as "teleosts" in Fig. 4), although the vast majority of these data originate from a single research cruise in March 1986 and from a very limited number of haul stations.

For herring, many detailed diet composition studies of have been published, starting with Hardy (1924) and Jes- persen (1928). In the Norwegian Sea diet has been shown to vary depending on availability of food and geographic location (Prokopchuk and Sentyabov, 2006; Langøy et al., 2012). C. finmarchicus is an important prey in summer (about $77 \%$ by weight), but in certain years appendicularians (Oikopleura spp.), amphipods (mainly Themisto abyssorum), and euphausiids are important. Similar variability has been noted for the North Sea, where pteropod molluscs (Limacina retroversa), sand eel (Ammodytes spp.) larvae, diatoms and the copepod Temora longicornis can also be locally important (Hardy, 1924; Savage, 1931). In the EURO-BASIN data set (Pinnegar et al., 2013), copepods dominated herring diets in terms of numerical abundance in the Norwegian Sea, Iceland, North Sea and west of Scotland $(69,85,66,74 \%$ respectively, Fig. 5). Hyperiid amphipods contributed a significant additional proportion in the Norwegian Sea (24\%), appendicularians contributed a significant but smaller proportion in the North Sea $(15 \%)$ and barnacle cypris larvae $21 \%$ in the west of Scotland. In eastern Greenland/northern Iceland (ICES Division XIV), euphausiids were the dominant prey item $(63 \%)$, followed by copepods $(16 \%)$ and hyperiid amphipods (15\%). In the Irish Sea euphausiids comprised $49 \%$ of the diet and fish eggs (denoted as "teleosts" in Fig. 5, but mostly plaice Pleuronectes platessa) contributed a further $31 \%$. However, these Irish Sea research cruises (in February 2009, 2010 and 2011) were deliberately timed to quantify the seasonal predation mortality imparted by pelagic fish on plaice eggs and larvae, so it is not surprising that this particular prey item featured strongly.

It would be very desirable to include information on prey availability within the database, however at present this is not feasible. The data included span more than a century and in most cases the scientists involved did not collect zooplankton information at the same time as sampling fish stomachs. 


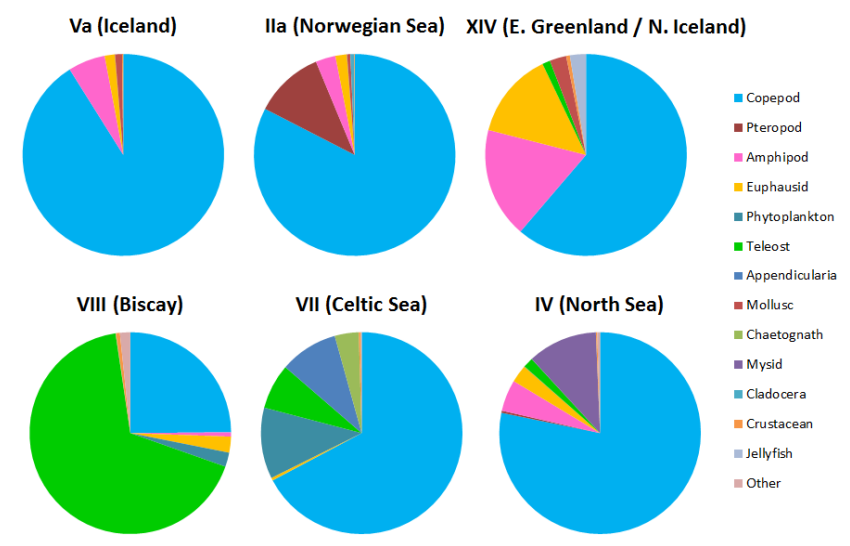

Figure 4. Diet composition of mackerel Scomber scombrus in different parts of the northeast Atlantic (ICES Divisions). Proportions are based on the number of individual prey items.

Unfortunately it is not possible to go back in time and supplement the data collected. For the most recent data on herring, blue whiting and mackerel, one might try to match the sample location, dates and times with corresponding information from the North Atlantic-wide Continuous Plankton Recorder survey (CPR, see Edwards et al., 2014), but this would be a complicated task to achieve and would require a separate research paper/analysis. For some of the earlier data sets (included in the "Cefas historical" sub-set), plankton data were collected, but these were largely qualitative in nature and not digitized as part of the DAPSTOM initiative. A global atlas of marine macro and meso-plankton data was published in Earth System Science Data in 2013 (see Moriarty and O'Brien, 2013; Moriarty et al., 2013) and hence these data sets could be used together with CPR data (Edwards et al., 2014) to characterize prey availability.

Albacore diet composition in the northeast Atlantic has been reported as being dominated by small, mesopelagic fish, e.g. Maurolicus muelleri (pearlside) and Scomberesox saurus (Atlantic saury), as well as euphausiids and hyperiid amphipods (Pusineri et al., 2005; Goñi et al., 2011). In the AZTI data submitted to PANGAEA (Goñi, 2014) similar patterns were observed, with euphausiids being dominant and the most ubiquitous prey in albacore. Albacore diet displayed high plasticity with important spatial variability, both latitudinally and in terms of oceanic vs. shelf-break waters. Among small pelagic fish species, Maurolicus muelleri was less abundant in these samples than in previous studies, whereas Atlantic saury, blue whiting and anchovy (Engraulis encrasicolus) were the major prey in the shelf-break areas of the Bay of Biscay and Celtic Sea. There was also considerable latitudinal variability in Atlantic saury consumption by albacore. This prey represented a larger proportion of albacore diet in northern sampling areas than within the Bay of Biscay. This corroborates previous observations by Aloncle and Delaporte (1974), who related the presence of Atlantic

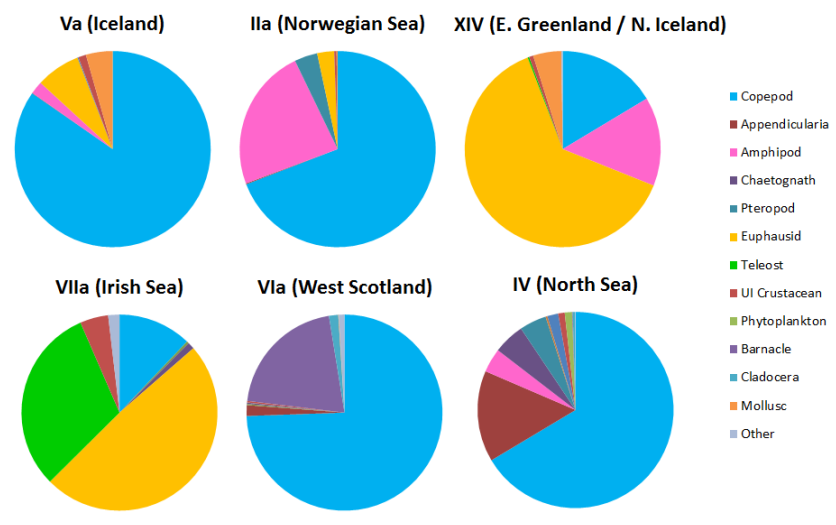

Figure 5. Diet composition of herring Clupea harengus in different parts of the northeast Atlantic (ICES Divisions). Proportions are based on the number of individual prey items.

saury to relatively low sea surface temperatures (SSTs) found out of the Bay of Biscay. This result suggests a potential higher predation impact on Atlantic saury when the summer distribution of albacore shifts westwards, as in 2009-2011.

Blue whiting consumption by albacore appeared to be related to the shelf-break of the Bay of Biscay and Celtic Sea but did not vary significantly with latitude. Consumption patterns suggested very marked inter-annual variation, with particularly low presence in albacore diet in 2010 and 2011 compared to 2005-2007. Taking into account the observed decrease in blue whiting biomass in recent years (Payne et al., 2012), this decrease in blue whiting consumption by albacore was likely related to a lower availability of the prey rather than to a shift in feeding preferences. This is corroborated by the observed proportion of blue whiting in the diet of bluefin tuna, which were sampled mostly in shelf-break locations.

Anchovy consumption also displayed considerable variability, being higher in the late summer and autumn in the southern Bay of Biscay (Fig. 6). The results suggest a broader spatial distribution of anchovy in albacore diet during 20092011 than during 2005-2007. This broader distribution was probably related to the recovery of the anchovy population after a period of collapse between 2005 and 2008 in the Bay of Biscay. The combined variability of the spatial extension of juvenile anchovies and of albacore distribution in summer months results in a distinct spatial match/mismatch and predation impact each year.

Bluefin tuna diet in the northeast Atlantic has been reported by Logan et al. (2011). In the Bay of Biscay, euphausiids (Meganyctiphanes norvegica) and anchovy made up $39 \%$ of prey weight, with relative consumption of each reflecting annual changes in prey abundance. Regarding anchovy consumption in particular, the same seasonal variability pattern as in albacore was apparent in bluefin tuna diet. This seasonal variability in both predators is likely to be related to the anchovy life-cycle and to the ecology of juvenile stages. Adult anchovies usually spawn on the continental shelf dur- 


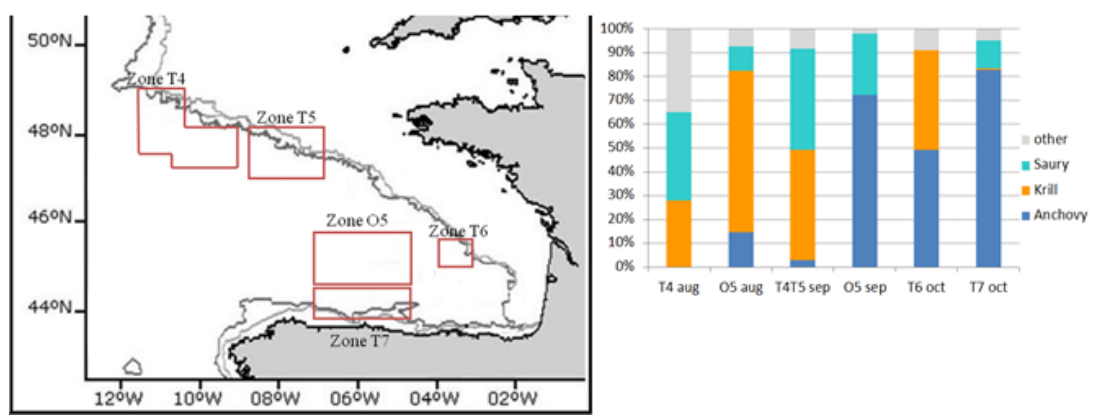

Figure 6. Diet composition of albacore sampled in distinct areas and periods in the Bay of Biscay during the summer and autumn of 2010.

ing spring. After a planktonic phase, juveniles start forming monospecific schools and leaving the continental shelf to reach oceanic waters (Irigoien et al., 2007) from early August onwards. This shift from the continental shelf to oceanic waters explains the higher consumption of juvenile anchovy by bluefin tunas in the second half of the summer. We also observed inter-annual variability in anchovy consumption, apparently following the interannual variations in anchovy recruitment and distribution.

Blue whiting is an important prey for bluefin tuna, especially in the first half of the summer when juvenile anchovies are not available. As with albacore, the data suggest a decrease in blue whiting consumption in the most recent years, following a decrease in recruitment (Payne et al., 2012). Atlantic saury, possibly because of the effect of SST on their distribution, were not as prevalent in bluefin tuna diet as they were in albacore diet, as bluefin tunas were exclusively sampled in the southeastern part of the Bay of Biscay. However, the results did suggest a higher proportion of saury in bluefin diet in 2011, when it seemed to partly replace anchovy as a high-caloric prey. Bluefin tuna used to be distributed in the North Sea, from where it disappeared in the 1960s. It is thought that in the past they fed primarily on herring and on mackerel in this region (Tiews, 1978). Occasional individuals have been recorded in the North Sea and around the British Isles in recent years. The few recent records contained in the EURO-BASIN/DAPSTOM data set (Pinnegar et al., 2013) suggest that they are now targeting similar prey animals as was the case in the past.

Herring stocks in the northeast Atlantic support some of the largest fisheries in the World, with total catches in 2011 amounting to 1.5 million tonnes. Mackerel and blue whiting also support important fisheries, and together these three species, with very large spawning stock biomasses (11.2, 2.7 and 3.8 million tonnes respectively in 2011), exert significant predation pressure on other commercial fish through feeding on fish eggs and larvae as well as depleting the standing stock of mesozooplankton (Engelhard et al., 2014). Small pelagic fish are themselves important prey items for larger predators, most notably tunas, but also seabirds and marine mammals in the North Atlantic. The total biomass of albacore in the
North Atlantic has been estimated at 76000 tonnes (in 2012) and bluefin tuna at 285000 tonnes (ICCAT, 2014). Within EURO-BASIN, the data sets described in this paper will be used to calculate overall predation pressure exerted by the various species. The longer-term aspiration (through making these data sets available via PANGAEA and DAPSTOM) is that this action will facilitate the construction of more realistic ecosystem or multispecies fisheries models that can subsequently be used to provide multispecies advice, as now mandated by international conventions and EU Directives.

Acknowledgements. Research leading to these results received funding from the European Commission FP7 project EURO-BASIN (European Basin-Scale Analysis, Synthesis, and Integration, Grant Agreement 264 933). Development of the DAPSTOM data portal was initially supported through a "data rescue" grant from the EU Network of Excellence programme "EurOceans". Further iterations were supported by the UK Department for Environment, Food and Rural Affairs (specifically contracts MF1202 and MF1109). AZTI tuna stomach sampling was funded through four research projects supported by the Basque Government (Agriculture and Fisheries Department).

Edited by: G. Melvin

\section{References}

Aloncle, H. and Delaporte, F.: Données nouvelles sur le germon atlantique Thunnus alalunga Bonnaterre 1788 dans le nord-est Atlantique. 2ème Partie. Rev. Trav. Inst. Pêches Marit., 38, 5102, 1974.

Brook, G. and Calderwood, W. L.: Report on the food of herring, in: Appendix F, VI - Preliminary reports on the food of fishes. Fourth Annual Report of the Fishery Board for Scotland, being for the year 1885, 102-128, 1886.

Brose, U., Jonsson, T., Berlow, E. L., Warren, P., Banasek-Richter, C., Bersier, L. F., Blanchard, J. L., Brey, T., Carpenter, S. R., Blandenier, M. F., Cushing, L., Dawah, H. A., Dell, T., Edwards, F., Harper-Smith, S., Jacob, U., Ledger, M. E., Martinez, N. D., Memmott, J., Mintenbeck, K., Pinnegar, J. K., Rall, B. C., Rayner, T. S., Reuman, D. C., Ruess, L., Ulrich, W., Williams, R. J., Woodward, G., and Cohen, J. E.: Consumer-resource body- 
size relationships in natural food webs, Ecology, 87, 2411-2417, 2006.

Bullen, G. E.: Plankton studies in relation to the western mackerel fishery, J. Mar. Biol. Assoc. UK, 8, 269-302, 1908.

Dolgov, A. V., Yaragina, N. A., Orlova, E. L., Bogstad, B., Johannesen, E., and Mehl, S.: 20th anniversary of the PINRO-IMR cooperation in the investigations of feeding in the Barents Sea results and perspectives, in: Proceedings of the 12th NorwegianRussian Symposium, Tromsø, 21-22 August 2007, IMR/PINRO Report Series, 44-78, 2007.

EC: Reform of the Common Fisheries Policy, Communication from the Commission to the European Parliament, the Council, the European Economic and Social Committee and the Committee of the Regions, $\operatorname{COM}(2011)$ 417, 2011.

Edwards, M., Helaouet, P. , Johns, D. G., Batten, S., Beaugrand, G., Chiba, S., Hall, J., Head, E., Hosie, G., Kitchener, J., Koubbi, P., Kreiner, A., Melrose, C., Pinkerton, M., Richardson, A. J., Robinson, K., Takahashi, K., Verheye, H. M., Ward, P., and Wootton, M.: Global Marine Ecological Status Report: results from the global CPR survey 2012/2013, SAHFOS Technical Report, 10, 1-37, 2014

Engelhard, G. H., Peck, M. A., Rindorf, A., Smout, S. C., van Deurs, M., Raab, K., Andersen, K. H., Garthe, S., Lauerburg, R. A. M., Scott, F., Brunel, T., Aarts, G., van Kooten, T., and DickeyCollas, M.: Forage fish, their fisheries, and their predators: who drives whom?, ICES J. Mar. Sci., 71, 90-104, 2014.

Goñi, N.: Stomach content records of albacore (Thunnus alalunga) and bluefin tuna (Thunnus thynnus) in the North Atlantic Drift Region focusing on the Bay of Biscay between 2004 and 2011, doi:10.1594/PANGAEA.826992, 2014.

Goñi, N., Logan, J., Arrizabalaga, H., Jarry, M., and Lutcavage, M.: Variability of albacore (Thunnus alalunga) diet in the Northeast Atlantic and Mediterranean Sea, Mar. Biol., 158, 1057-1073, 2011.

Hardy, A. C.: The herring in relation to its animate environment. Part I. The food and feeding habits of the herring with special reference to the east coast of England, MAFF Fishery Investigations II, 7, 1-39, 1924.

Hyslop, E. J.: Stomach contents analysis - a review of methods and their application, J. Fish Biol., 17, 411-429, 1980.

ICCAT: Report for biennial period, 2012-13, Part II (2013) - Vol. 2, SCRS. International Commission for the Conservation of Atlantic Tunas, 343 pp., 2014.

ICES: Report of the study group on multispecies model implementation in the Baltic. International Council for the Exploration of the Sea, ICES CM 1997/J:2, 1997.

ICES: Multispecies considerations for the North Sea stocks, ICES Advice 2013, Book 6, section 6.3.1, June 2013, International Council for the Exploration of the Sea, Copenhagen, Denmark, 2013.

Irigoien, X., Fiksen, Ø., Cotano, U., Uriarte, A., Alvarez, P., Arrizabalaga, H., Boyra, G., Santos, M., Sagarminaga, Y., Otheguy, P., Etxebeste, E., Zarauz, L., Artetxe, I., and Motos, L.: Could Biscay Bay anchovy recruit through a spatial loophole?, Prog. Oceanogr., 74, 132-148, 2007.

Jespersen, P.: Investigations on the food of the herring in Danish waters, Medd. Komm. f. Havundersoegelser, Serie Plankton, 2, 1-149, 1928.
Langøy, H., Nøttestad, L., Skaret, G., Broms, C., and Fernö, A.: Overlap in distribution and diets of Atlantic mackerel (Scomber scombrus), Norwegian spring-spawning herring (Clupea harengus) and blue whiting (Micromesistius poutassou) in the Norwegian Sea during late summer, Mar. Biol. Res., 8, 442-460, 2012.

Last, J. M.: The food of twenty species of fish larvae in the westcentral North Sea, MAFF Fisheries Research Technical Report 60, 44 pp., 1980.

Lebour, M. V.: The food of young clupeoids, J. Mar. Biol. Assoc. UK, 12, 458-467, 1921.

Lebour, M. V.: The food of young herrings, J. Mar. Biol. Assoc. UK, 13, 325-330, 1924.

Le Quesne, W. J. F. and Pinnegar, J. K.: The potential impacts of ocean acidification: scaling from physiology to fisheries, Fish. Fish., 13, 333-344, 2012.

Logan, J. M., Rodríguez-Marín, E., Goñi, N., Barreiro, S., Arrizabalaga, H., Golet, W., and Lutcavage, M.: Diet of young Atlantic bluefin tuna (Thunnus thynnus) in eastern and western Atlantic foraging grounds, Mar. Biol., 158, 73-85, 2011.

Mackinson, S., Deas, B., Beveridge, D., and Casey, J.: Mixedfishery or ecosystem conundrum? Multi-species considerations inform thinking on long-term management of North Sea demersal stocks, Can. J. Fish. Aquat. Sci., 66, 1107-1129, 2009.

Marshall, S. R., Nicholls, A. G., and Orr, A. P.: On the growth and feeding of the larval and post-larval stages of the Clyde herring, J. Mar. Biol. Assoc. UK, 22, 245-267, 1937.

Marshall, S. R., Nicholls, A. G., and Orr, A. P.: On the growth and feeding of young herring in the Clyde, J. Mar. Biol. Assoc. UK, 23, 427-455, 1939.

Mehl, S. and Westgård, T.: The diet and consumption of mackerel in the North Sea, International Council for the Exploration of the Sea, ICES CM 1983/H:34, 1983.

Moriarty, R. and O'Brien, T. D.: Distribution of mesozooplankton biomass in the global ocean, Earth Syst. Sci. Data, 5, 45-55, doi:10.5194/essd-5-45-2013, 2013.

Moriarty, R., Buitenhuis, E. T., Le Quéré, C., and Gosselin, M.P.: Distribution of known macrozooplankton abundance and biomass in the global ocean, Earth Syst. Sci. Data, 5, 241-257, doi:10.5194/essd-5-241-2013, 2013.

Payne, M. R., Egan, A., Fässler, S. M. M., Hátún, H. L., Holst, J. C., Jacobsen, J. A., Slotte, A., and Loeng, H.: The rise and fall of the NE Atlantic blue whiting (Micromesistius poutassou), Mar. Biol. Res., 8, 475-487, 2012.

Pinnegar, J. K.: DAPSTOM - An Integrated Database \& Portal for Fish Stomach Records, Version 4.7, Centre for Environment, Fisheries \& Aquaculture Science (Cefas), Lowestoft, UK, February 2014, 39 pp., 2014.

Pinnegar, J. K., Trenkel, V. M., Melle, W., and Óskarsson, J. G.: Stomach content records for pelagic fish (herring, mackerel, blue whiting, albacore and bluefin tuna) in the northeast Atlantic, doi:10.1594/PANGAEA.820041, 2013.

Prokopchuk, I. and Sentyabov, E.: Diets of herring, mackerel, and blue whiting in the Norwegian Sea in relation to Calanus finmarchicus distribution and temperature conditions, ICES J. Mar. Sci., 63, 117-127, 2006.

Pusineri, C., Vasseur, Y., Hassani, S., Meynier, L., Spitz, J., and Ridoux, V.: Food and feeding ecology of juvenile albacore, Thunnus alalunga, off the Bay of Biscay: a case study, ICES J. Mar. Sci., 62, 116-122, 2005. 
Rochet, M.-J., Collie, J. S., Jennings, S., and Hall, S. J.: Does selective fishing conserve community biodiversity? Predictions from a length-based multispecies model, Can. J. Fish. Aquat. Sci., 68, 469-486, 2011.

Rossberg, A. G., Farnsworth, K. D., Satoh, K., and Pinnegar, J. K.: Universal power-law diet partitioning by marine fish and squid, with surprising stability-diversity implications, P. Roy. Soc. BBiol. Sci., 278, 1617-1625, 2011.

Savage, R. E.: The relation between the feeding of herring off the East coast of England and the plankton of the surrounding waters, MAFF Fishery Investigations II, 12, 1-88, 1931.
Scott, A.: Food of the Irish Sea Herring in 1923, in: Proceedings and Transactions of the Liverpool Biological Society, 38, 115119, 1924.

Tiews, K.: On the disappearance of bluefin tuna in the North Sea and its ecological implications for herring and mackerel, Rapp p.-v. Reun., 172, 301-309, 1978. 